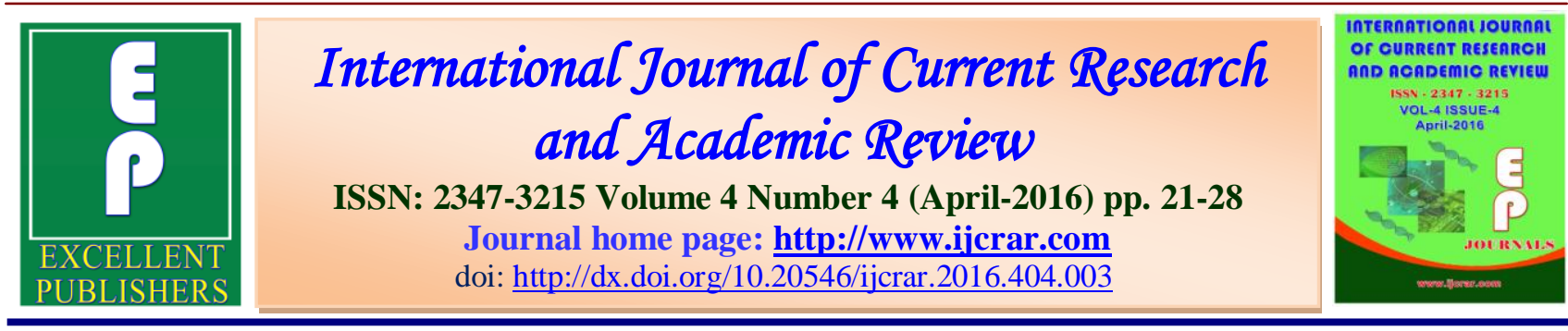

\title{
Admission Pattern and Outcome of Patients Attending a Tertiary Care Hospital
}

\author{
Bishnu Ram Das ${ }^{1}$, Anuradha Hazarika Medhi ${ }^{2}$, Netri Das ${ }^{3}$, Gitali Kakoti ${ }^{4}$, Gunjan \\ Nath $^{5}$ and Abu Hasan Sarkar ${ }^{5}$
}

${ }^{1}$ Professor \& Head, Department of Community Medicine, Jorhat Medical College, Jorhat785001, Assam, India

${ }^{2}$ Lecturer in Biostatistics, Department of Community Medicine, Jorhat Medical College, Jorhat-785001, Assam, India

${ }^{3}$ Assistant Professor, Department of Community Medicine, Jorhat Medical College, Jorhat785001, Assam, India

${ }^{4}$ Former Women Scientist-A (DST) \& PhD Scholar, Regional Medical Research Centre, ICMR, Northeast Region, Post Box no. 105, Dibrugarh, Assam, India

${ }^{5}$ PGT, Department of Community Medicine, Jorhat Medical College, Jorhat-785001, Assam, India

*Corresponding author

\section{KEYWORDS}

Tertiary,

Admission profile, Out

Patients Department

(OPD), In Patients

Department (IPD),

Bed Occupancy Rate

(BOR),

Discharge Against

Medical Advice

(DAMA).

\section{A B S T R A C T}

Hospital admissions pattern helps to understand the acceptability and utilization of health care services and also indicates the disease burden prevailing in the serving community. This study is an attempt to determine the current pattern of admissions and their clinical outcomes at a tertiary care hospital in Assam. A retrospective record-based study was conducted in Jorhat Medical College and Hospital from 2011 to 2014. A total of 9, 10,157 patients have attended the Out Patient Department (OPD) and 1,28,824 patients were admitted to the In Patients Department (IPD). The daily average of patients attended the OPD ranges between 688-848 and about 77 to 98 patients were admitted to the IPD. In OPD, majority of the patients attended medicine department (19.5\%) followed by Emergency (15.4\%) and Orthopedics $(10.2 \%)$ department. Similar pattern was observed in the IPD with Medicine having the highest case load (30.5\%) followed by Obstetrics and Gynaecology $(25.6 \%)$ and Surgery (16.7\%). The rural urban patient ratio was calculated as 60:40. The Bed Occupancy Rate (BOR) of the hospital was found 87.8\%. Approximately 3\% patients died in hospital, $80 \%$ improved and $12 \%$ were referred to other institution. We could not evaluate the status of $5 \%$ patients who were Discharged Against Medical Advice (DAMA). Our study indicates that the services provided by this teaching hospital are acceptable to the community and showing an increasing trend of patient flow with efficient bed occupancy rate. Majority of the admitted patients were discharged from the hospital on improvement. For a newly established government hospital it may be labelled as time-honoured advancement. 


\section{Introduction}

Hospital admissions pattern are a reflection of the prevailing burden of diseases in the community. Even though it may not be a true reflection of the actual disease burden in the general population, they give insight into the disease burden in the community and are also valuable in evaluating the health care system of the region.

There is variation in pattern of admissions which partly result from the referral and admission process that is via general practitioner, other hospital or self referral to tertiary care hospital. Hospitals deal with the life and health of their patients. Tertiary health care institutions play a very important role in health care delivery systems as they handle referrals from primary and secondary health institutions and treat serious sickness compared to other levels of health care delivery systems. So, medical admissions constitute a very significant part of general admissions in many hospitals and they are a reflection of common diseases in the society $(1,2,3)$.

Study of hospital admissions pattern in terms of different specialty and patients' outcome are very useful in performance evaluation of a hospital, health care planning and in a bid to improve service delivery to the society. Understanding of epidemiological trends in hospital admissions, including outcome pattern helps in appropriate allocation of scarce resources in developing country $(5,6)$.

There is little information on the hospital admissions pattern and outcome of admitted patients in medical college hospitals of Assam. An attempt was made to understand the current pattern of admissions in different specialties and their clinical outcomes at the time of discharge in Jorhat Medical College \& Hospital of Assam.

\section{Materials and Methods}

A retrospective record based study was carried out at Jorhat Medical College and Hospital (JMCH), Jorhat over a period of 4 years from January 2011 to December 2014. All the patients admitted during the period were enrolled as study participants. JMCH which is a tertiary care hospital of Assam is situated at the centre of Jorhat district serving both urban and rural population of Assam. The hospital was upgraded to a medical college in 2009 from a district level hospital. Observing the increasing flow of patients over the years, the bed strength was increased in the year 2013 from 300 beds to 500 beds. Patients are admitted either from outpatient departments or from casualty. Admitted patients either come directly to the hospital or are referred from primary /secondary care Govt hospitals, local general practitioner and other private hospitals. The medical records of all admissions whose records were available reviewed for age, gender, residence, specialty of admission and final outcome at discharge. Data was obtained from the patient's records preserved by the Medical Record Department (MRD) of the hospital. Outcome information were also collected from the patients registers recorded in the MRD of the hospital and analysed as discharged, death, referred, and Discharged Against Medical Advice (DAMA).

Ethical clearance was obtained from the Institutional Ethical Review committee of the College.

In the present study, the bed occupancy rate (BOR) was calculated as defined in following formula:

$\mathrm{BOR}=$

$\frac{\text { Average no.of beds occupied in a particular period }}{\text { Bed compliment in that period }} \times 100$ 


\section{Statistical Analysis}

The data obtained from secondary sources were classified and analyzed statistically by using MS Excel and SPSS-18 (Statistical Package for Scientific Solution) Trial version. Statistical analysis was done using mean, percentage, range and ratio as per applicable. The two-tailed chi square test was used for testing significance of categorical data at $5 \%$ level of significance.

\section{Results and Discussion}

The total no. of patients attending the OPD during the study period of 2011-2014 was 9, 10, 157 and 1, 28,824 patients were admitted into the IPD during the said duration (Table-1). On an average 688-848 patients attended the OPD and 77-98 patients were admitted to the IPD on a daily basis in 4 years study period. The study reveals that there was an increasing trend in OPD and IPD patients over the 4 years.

Table-2 shows the socio- demographic profile of the patients admitted in the hospital from 2011 to 2014. It was observed that $24 \%$ of admitted patients were belong to reproductive age group (15-49 years), 12.6\% patients were below 12 years of age and were admitted in Paediatrics department while another $13.2 \%$ belonged to Geriatric age group. Male patients constituted 54.8\% of all admitted patients while females constituted $45.2 \%$ during the study period. However, it was seen that there was no significant difference between the male and female admitted patients over the four years. $(\mathrm{p}=0.1096)$ It was also observed that majority $(60 \%)$ of all admitted patients belonged to rural community. There was a significant difference between rural and urban admitted patients $(\mathrm{p}=0.0444)$.

Overall there are thirteen (13) specialty departments in OPD in the hospital. Table-3 shows the distribution of patients attending the different specialty of OPD during the study period 2011- 2014. It was observed that majority of patients attended the Medicine OPD (18.7\%).

The Emergency department secured second position (15.4\%) followed by Orthopaedics (10.2\%), Surgery OPD (10\%) and obstetrics and Gynaecology (9.6\%) On the other hand, it was found that TB \& Chest $(0.3 \%)$ and Geriatric $(0.5 \%)$ OPDs secured the lowest attendance. The data shows a gradual increase in the proportion of patients attending the different departments of OPD over the study period.

In IPD, maximum patients were admitted in Medicine department (30.5\%) followed by Obstetrics \& Gynaecology (25.6\%) and Surgery Department (16.7\%). At least $0.1 \%$ of patients were admitted to both Cardio Critical Care Unit and Dermatology Departments which were the lowest among all the Departments. However, these two departments were opened in the hospital only in the year 2014. There was a rising trend in the number of patients admitted in various departments of the hospital over the years. (Figure-1)

The bed strength of Jorhat Medical College Hospital for the year 2014 was 500 as per hospital records. Based on this information, the Bed Occupancy rate for the hospital was found as $87.8 \%$ for the year 2014 .

Figure-2 shows the clinical outcome of the patients over the four years. The study reveals that discharge after improvement constituted the largest part of outcome $(80 \%)$ while about $12 \%$ patients were referred to other institutions for better treatment. $3 \%$ patients died in the hospital over the period and $5 \%$ patients were considered for Discharge against Medical Advice. 
It was also observed in our study that the number of deaths showed a steady decline over the study period of 2011-2014 (25.4\% in $2011,25.3 \%$ in $2012,24.6 \%$ in 2013 and $24.5 \%$ in 2014). Again, death rate of the hospital was obtained as $3.4 \%, 2.9 \%, 2.8 \%$ and $2.6 \%$ for the four respective years. As a whole, the average death rate of the hospital for the study period was found as $2.9 \%$.

It has been seen that a huge numbers of patients availed health care services from this tertiary care teaching hospital. Admission of patients showed an increasing trend over years in both OPD and IPD. The results are similar to the findings of other tertiary care hospitals. This shows that services rendered by this hospital are accessible and acceptable to the serving community. This may be due to an incremental improvement in health care facilities and service delivery of the hospital $(8,9,10)$.

The present study shows that among the admitted patients, there was no significant difference between male and female patients. Similar results had also been observed in some other studies conducted in tertiary care hospitals. In the current study we found that approximately only $12.6 \%$ of patients who were below 12 years were admitted in Paediatrics department which is similar to another study showing nearly $13 \%$ paediatric cases among admitted patients. ${ }^{6}$ This may be due to the preference of many care givers to take their children to Private health institutions for better treatment.

Again our study revealed that women of reproductive age group contributed to $24 \%$ of total hospital admissions which were highest of the total hospital admission. This high admission rate is a direct impact of Janani Surakshya Yojana currently implementing under National Health Mission.
We found $13.2 \%$ Senior Citizens were hospitalised due to various ailments during the study period. Similar observation also made by in an study conducted at All India Institute of Medical Sciences (AIIMS), New Delhi, India, where it was observed that almost $10 \%$ of admitted patients were in the 70 plus age group.

Moreover, our study revealed that rural resident comprised a significantly higher proportion (60\%) of the admitted patients. Similar findings were observed by other researchers. This may be due to the fact that even today a large part of the population of India resides in rural areas (10).

Of the total patients maximum have attended the Medicine OPD (19.5\%), followed by the Emergency department (15.4\%) and Orthopaedics OPD (11\%) while in others OPD attendance ranged from $0.5 \%$ to $10 \%$.

In IPD maximum patients were admitted in Medicine department (30.5\%), Obstetrics \& Gynaecology department (25.6\%) and Surgery Department (16.7\%). However, observing the hospital data (IPD) of another tertiary care hospital of Assam, we had found a little difference which showed that the majority of patients attended in Surgery (24\%), Medicine (22\%) and Obstetrics \& Gynaecology (18\%) departments.

Admission rate was relatively low in the Cardio Critical Care Unit (CCU) and Dermatology Departments in IPD $(0.1 \%$ each). This may be explained that the study hospital do not have cardiology super speciality and patient may have preferred to avail cardiac services from nearby other institute. On the other hand dermatology cases are mostly treated in outpatient department or services are mostly availed from peripheral community hospital. 
Int.J.Curr.Res.Aca.Rev.2016; 4(4): 21-28

Table.1 No. of Patients Attended in OPD and IPD Admission

\begin{tabular}{|c|c|c|c|c|}
\hline \multirow{2}{*}{ Year } & \multicolumn{2}{|c|}{ OPD } & \multicolumn{2}{c|}{ IPD } \\
\cline { 2 - 5 } & Total patients & Percentage & Total patients & Percentage \\
\hline 2011 & 199761 & 21.9 & 27991 & 21.7 \\
\hline 2012 & 208500 & 22.9 & 32041 & 24.9 \\
\hline 2013 & 244808 & 26.9 & 32881 & 25.5 \\
\hline 2014 & 257088 & 28.3 & 35911 & 27.9 \\
\hline Total & $9,10,157$ & 100 & $1,28,824$ & 100 \\
\hline
\end{tabular}

Table.2 Socio-demographic Profile of Admitted Patients

Distribution by Age

\begin{tabular}{lc}
\hline Age & Percentage $(\boldsymbol{\%})$ \\
\hline Below 12 years & 12.6 \\
12-60 years* & 74.2 \\
Above 60 years & 13.2 \\
\hline
\end{tabular}

*24\% women belong to the reproductive age group

Distribution by Gender

\begin{tabular}{lccccc}
\hline Year & Male & \% & Female & \% & Total \\
\hline 2011 & 14471 & 51.7 & 13520 & 48.3 & 27991 \\
2012 & 16117 & 50.3 & 15924 & 49.7 & 32041 \\
2013 & 18874 & 57.4 & 14007 & 42.5 & 32881 \\
2104 & 21259 & 59.2 & 14652 & 40.8 & 35911 \\
Total & 70721 & 54.8 & 58103 & 45.2 & 128824 \\
\hline
\end{tabular}

$\mathrm{p}=0.1096$, Not significant

Distribution by Residence

\begin{tabular}{lcccc}
\hline Residence & Rural & \% & Urban & \% \\
\hline 2011 & 16795 & 59.9 & 11196 & 40.1 \\
2012 & 18872 & 58.9 & 13169 & 41.1 \\
2013 & 18873 & 57.4 & 14008 & 42.5 \\
2014 & 22337 & 62.2 & 13574 & 37.8 \\
Total & 76877 & 59.8 & 51947 & 40.2 \\
\hline
\end{tabular}

$\mathrm{p}=0.0444$, Significant 
Int.J.Curr.Res.Aca.Rev.2016; 4(4): 21-28

Table.3 Patient Load in OPD over 4 Years (2011-2014)

\begin{tabular}{|l|l|l|l|l|l|}
\hline Department & 2011 & 2012 & 2013 & 2014 & Total $(\%)$ \\
\hline MOPD & $40595(23.8 \%)$ & $40404(23.7 \%)$ & $42859(25.1 \%)$ & $46874(27.5 \%)$ & $170732(19.5)$ \\
\hline SOPD & $20666(22.5 \%)$ & $21476(23.4 \%)$ & $24296(26.5 \%)$ & $25216(27.6 \%)$ & $91654(10)$ \\
\hline Geriatric & N/A* & $285(6.8 \%)$ & $1724(41.2 \%)$ & $2177(52.0 \%)$ & $4186(0.5)$ \\
\hline TB \& Chest & N/A* & $1263(28.3 \%)$ & $743(16.6 \%)$ & $2464(55.1 \%)$ & $4470(0.5)$ \\
\hline Paediatric & $14970(20 \%)$ & $15774(21 \%)$ & $21698(29.3 \%)$ & $22461(30 \%)$ & $74903(8.2)$ \\
\hline Dermatology & $13871(22.9 \%)$ & $14193(23.4 \%)$ & $17499(28.9 \%)$ & $14970(24.7 \%)$ & $60593(6.7)$ \\
\hline Psychology & $2807(23.3 \%)$ & $2961(24.5 \%)$ & $3016(25 \%)$ & $3283(27.2 \%)$ & $12067(1.3)$ \\
\hline Orthopaedics & $18773(20.3 \%)$ & $21938(23.7 \%)$ & $24974(27 \%)$ & $26766(29 \%)$ & $92451(10.2)$ \\
\hline Eye & $10965(20.6 \%)$ & $11625(21.9 \%)$ & $15398(29 \%)$ & $15109(28.4 \%)$ & $53097(5.8)$ \\
\hline ENT & $15155(22.2 \%)$ & $15332(22.5 \%)$ & $18021(26.4 \%)$ & $19562(24.3 \%)$ & $68070(7.5)$ \\
\hline Dental & $10237(22.3 \%)$ & $10199(22.2 \%)$ & $12211(26.6 \%)$ & $13240(28.9 \%)$ & $45887(5.1)$ \\
\hline $\begin{array}{l}\text { Obstetrics \& } \\
\text { Gynaecology }\end{array}$ & $20334(23.3 \%)$ & $21830(25.1 \%)$ & $22378(25.7 \%)$ & $22572(25.9 \%)$ & $87114(9.6)$ \\
\hline Emergency & $28695(20.4 \%)$ & $31220(22.3 \%)$ & $37991(27.7 \%)$ & $42394(30.2 \%)$ & $140300(15.4)$ \\
\hline $\begin{array}{l}\text { Total } \\
199761\end{array}$ & $208500(23 \%)$ & 244808 & 257088 & $910157(100)$ \\
$(21.9 \%)$ & & $(26.9 \%)$ & $84.9 \%)$ & \\
\hline $\begin{array}{l}\text { Daily } \\
\text { average }\end{array}$ & $691(22.8 \%)$ & $688(22.6 \%)$ & $808(26.7 \%)$ & $848(28 \%)$ & $3035(100)$ \\
\hline
\end{tabular}

*N/A - not available

Figure.1 Patient Load in IPD over 4 Years (2011-2014)

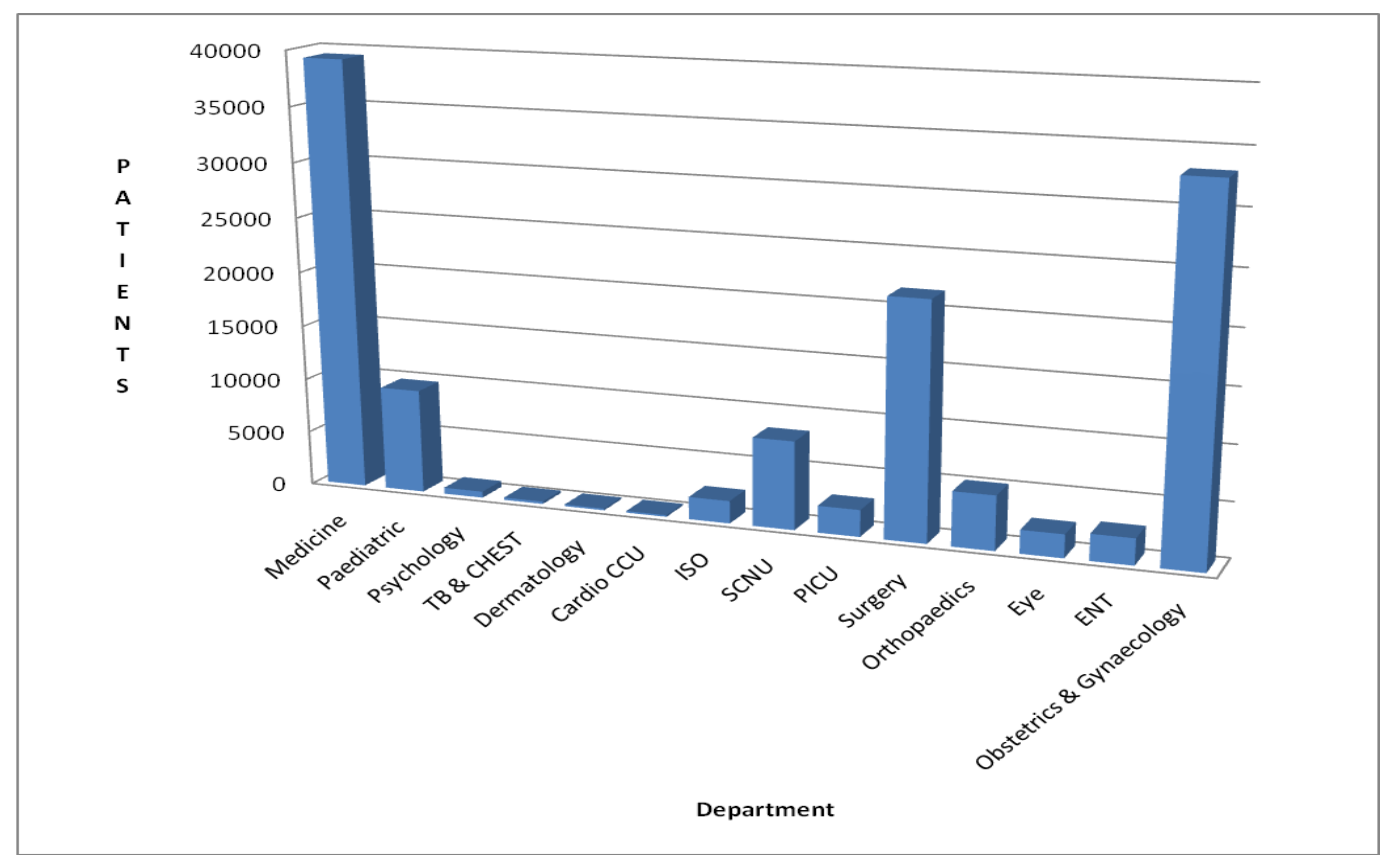




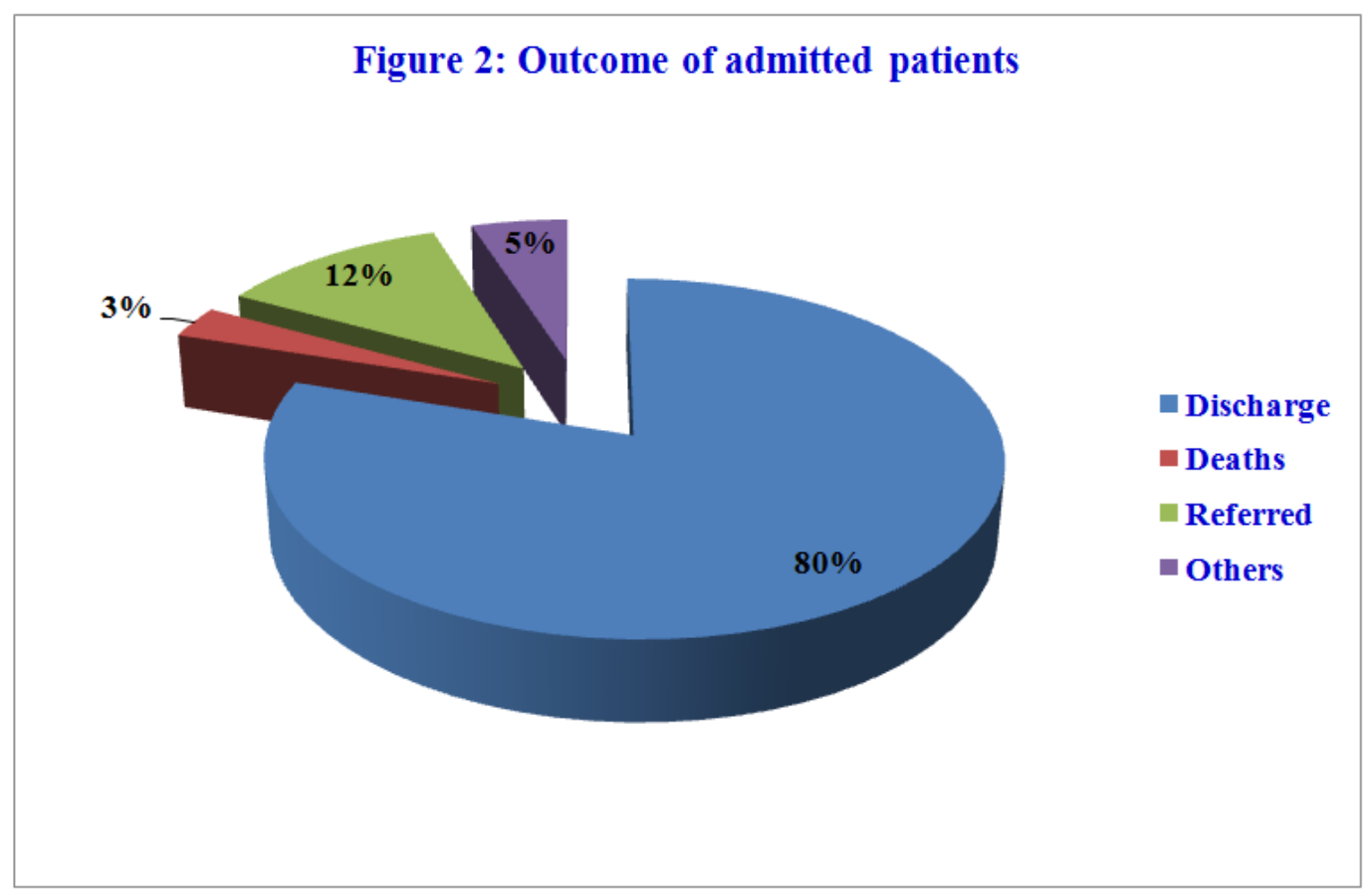

It is clear from our study that there was an increasing flow of patients to this teaching hospital. The hospital bed occupancy rate (BOR) was found as $87.8 \%$. According to the unit cost of Medical service at different hospitals in India, one of the efficiency indicators of hospital is BOR with $80 \%$. Our study results indicate that the services provided by the hospital are efficient. As a newly established government medical college, it may be accepted as an encouraging progress.

The current study reveals that discharge constituted the largest proportion of outcome $(80 \%)$ which resembles another study conducted in Nigeria. Referral rate was found to be $12 \%$ while $3 \%$ deaths occurred in the hospital during the study period. Also, $5 \%$ of total admitted patients were Discharged Against Medical Advice (DAMA). This may be due to poor economic status or illiteracy among the patients attending the facility. Similar pattern of outcome was observed in other studies carried out in tertiary care institutions The average death rate of the hospital was found as $2.9 \%$, which is similar to the hospital mortality rate of India. Similar findings were also observed in other studies $(3.5 \%$ and $2.5 \%)$. We observed a gradual decline in the number of deaths occurring in the hospital over the study period. Since our study site is a newly established medical college and there has been gradual improvement in health care service delivery in the hospital, so this may be a reason for this gradual decline in death rate over time. However, to ascertain it requires further in depth study.

\section{Limitations}

Since the present study was a retrospective record based study conducted in a tertiary care hospital, so some information were not available in the hospital registers or records. Again, as it is a newly established hospital, some departments were opened later. So admission data for all the study years could not retrieved. 


\section{Conclusion}

The present study was an attempt to analyse the admissions pattern and outcome of patients attending Jorhat Medical College and Hospital. We found an increasing trend of admission of patients with majority of patients hailing from rural areas. Most of the admitted patients were discharged from hospital once improved while the hospital mortality rate was 3\% during the study period. Study findings will help the hospital authority to focus and plan on the specific areas of manpower and infrastructure development as per patients load. This is needed to increase the efficiency and effectiveness of the various departments of the hospital. So that, one can expect better plan of hospital services and allocation of scarce health service resources in future.

\section{Acknowledgement}

The authors would like to acknowledge the Principal, Jorhat Medical College and hospital for providing permission to carry out the present study. The authors would also like to thank the Medical Records Department of the hospital for their cooperation and assistance while conducting the study.

\section{References}

1. Okunola, O.O., Akintunde, A.A., Akinwusi, P.O. 2012. Some emerging issues in medical admission pattern in the tropics. PUBMED. Niger J. Clin. Pract., 15: 51 -54.
2. Ravi Kiran, E., Vijaya, K. 2003. Utilization of Beds in a Tertiary care Hospital. JAHA, 15(2): (2003-07 - 2003-12).

3. Final-gmc visit report. Economic status of the indoor patients of Gauhati medical college and hospital (gmch),Guwahati, Assam.

4. Chattoraj, A., Satpathy, S. 2006. A study of sickness \& Admission pattern of patients attending an emergency department in a tertiary care hospital. J. Academy of Hosp. Admin., 18(1): (2006-01-2006-12).

5. Osarenkhoe, J., Omoruyi, L., Imarhisgbe, Adebayo, O., Freeman, O. 2015. Pattern and outcome of medical admission in a Nigerian rural teaching hospital (2009-2012). Annals of Trop. Med. Public Health, 7(3): 171-176.

6. Abhulimhen-Iyoha, B.I., Pooboni, S.K., Vuppali, N.K.K. 2014. Morbidity Pattern and Outcome of Patients Admitted into a Pediatric Intensive Care Unit in India. Indian J. Clin. Med., 5: 1 -5.

7. Clough, J.D., Kay, R., Gombeski, W.R., Jr, Nickelson, D.E., Loop, F.D. 1993. Mortality of patients transferred to a tertiary care hospital. Cleve Clin. J. Med., 60(6): 449 -454 .

8. Ghose, S., Adhish, S.V. 2011. Patient satishfaction with Medical service: A hospital-based study. Health and population, Perspectives and Issues, 34(4): 232-242.

9. Chatterjee, S., Levin, C., Laxminarayan, R. 2013. Unit Cost of Medical Services at Different Hospitals in Indi. PLoS One, 8(7): e69728. doi:10.1371/journal.pone.0069728

10. Kulkarni, S.K., Doibale, M.K. 2014. Mortality Trend In Tertiary Care Hospital Of Nanded In Maharashtra. Int. J. Basic and Appl. Med. Sci., 4(1): 372-373. ISSN:227http://www.cibtech. org/jms.htm72

\section{How to cite this article:}

Bishnu Ram Das, Anuradha Hazarika Medhi, Netri Das, Gitali Kakoti, Gunjan Nath and Abu Hasan Sarkar. 2016. Admission Pattern and Outcome of Patients Attending a Tertiary Care Hospital. Int.J.Curr.Res.Aca.Rev.4(4): 21-28. doi: http://dx.doi.org/10.20546/ijcrar.2016.404.003 